\section{ANATOMY OF THE TEETH 1}

$T \mathrm{O}$ the histologist, the zoologist, and the human anatomist the teeth are organs of considerable interest, from the points of view of their minute structure, their development, together with their variations, as well as from the diseases to which they are subject; and yet our literature has been deficient in a work on "Dental Anatomy, Human and Comparative." Text-books, such as Quain and Sharpey's "Anatomy," give us full information with reference to their structure, form, and development in man whilst in Owen's superb monograph on "Odontography," as in his "Anatomy of Vertebrated Animals," their zoological aspect is treated of in detail. Mr. Charles S. Tomes has filled the deficiency in the volume under consideration, in a manner so satisfactory that we feel assured that his work will take a high place among Messrs. Churchill's valuable "Manuals."

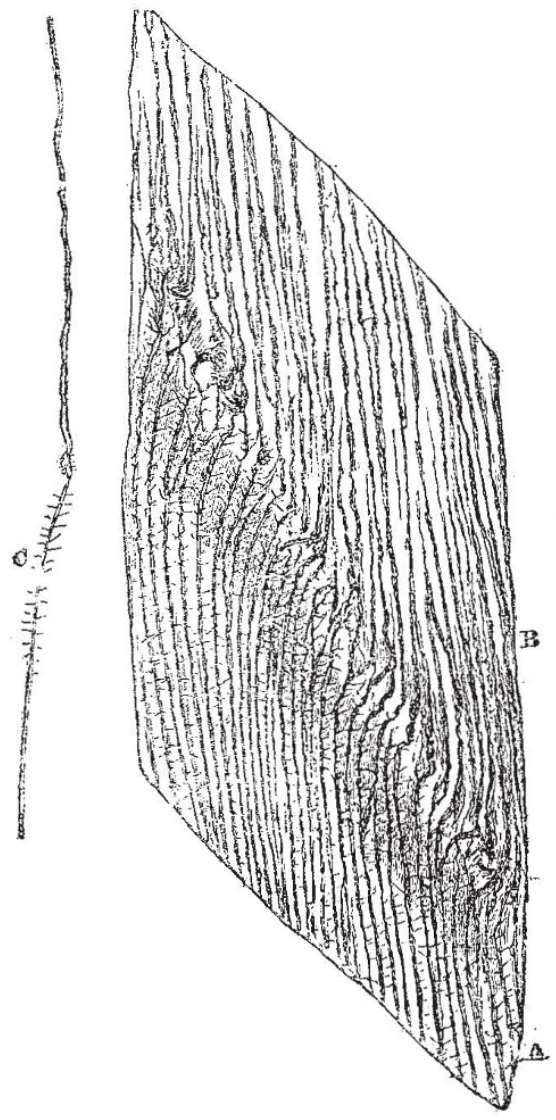

FIG. 2:

For some years past Mr. Tomes, "following his father's footsteps, has been carefully investigating the structure and development of the teeth, not so much in man as in the lower vertebrata; and his results have been published in the Proceedings of the Odontological Society, the Quarterly Fournal of Microscopical Science, the Transac. tions of the Royal Society, and elsewhere. In the work before us these results, many of them of considerable importance, are incorporated in the sections to which they refer, the book itself being an excellent epitome of our present knowledge of the development and structure of the teeth in man and the lower animals.

It is evident to all that a thorough acquaintance with comparative odontology cannot be obtained by anyone not familiar with the structure and development of the I "A Manual of Dental Anatomy, Human and Comparative." By C. S. Tomes, M.A. (I. and A. Churchill, 187 C) teeth. In the same way the facilities for investigating histological and embryological odontology are much enhanced by a knowledge of the comparative anatomy of the organs studied, as is the human dentition, although we would be among the last to make it a sine quâ non that our dentist should be thoroughly informed on this large view of the subject. It is, therefore, on these accounts that Mr. Tomes's Manual will appeal to more than one class of student.

The work commences with an account of the teeth of

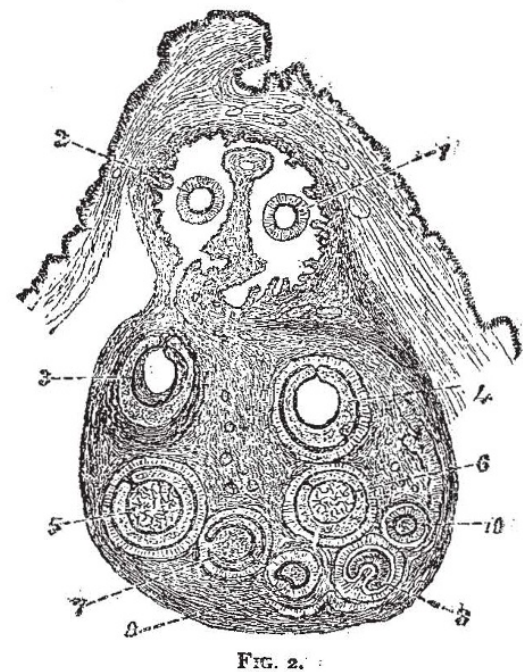

man and of the bones with which they are associated, "as" being the standard with which the student is likely, consciously or unconsciously, to compare those other forms with which he afterwards becomes acquainted." The dental tissues are next described, foliowed by the deve lopment and eruption of the teeth, the last two hundred pages being devoted to the zoological aspect of the subject.

The human teeth have been studied so thoroughly that $\mathrm{Mr}$. Tomes has nothing special, to tell us with reference

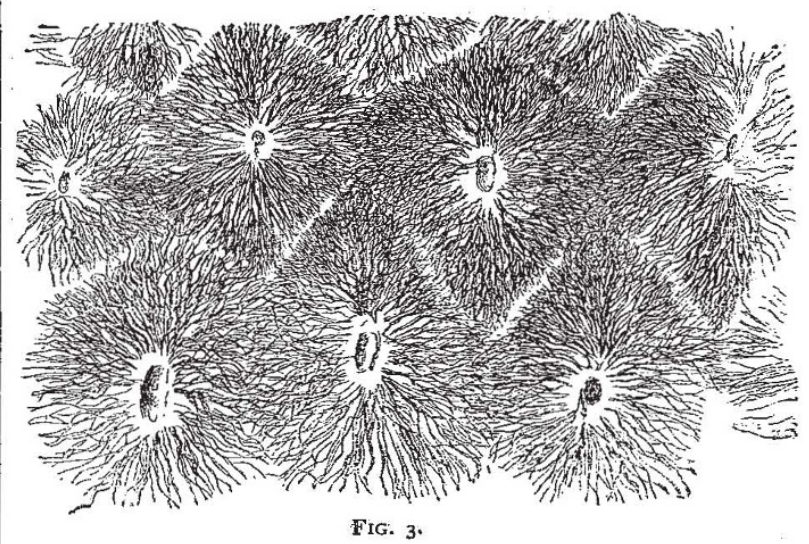

to them. As to their arrangement, his experience confirms the fact that, from the parabolic curve in which they are arranged in the typical human jaws, tending to squarish in the lowest races, "a deviation in the opposite direction is daily: becoming more common in the most highly civilised races, resulting in a contour to which in extreme cases the name of V-shaped maxilla is applied."

On the subject of the histology of the dental tissues we notice several interesting points. With reference to the presence of enamel in the lower vertebrata, we are told 
that a thin layer of this material is to be found in snakes, and that an enamel organ is always present, as in the frog and armadillo, where in the fully-formed tooth this tissue cannot be detected. We cannot refrain also from quoting a sentence with reference to a point of zoological interest which is frequently overlooked, for, says the author-“" as was pointed out by my father, the passage of the dentinal tubes into and through a great part of

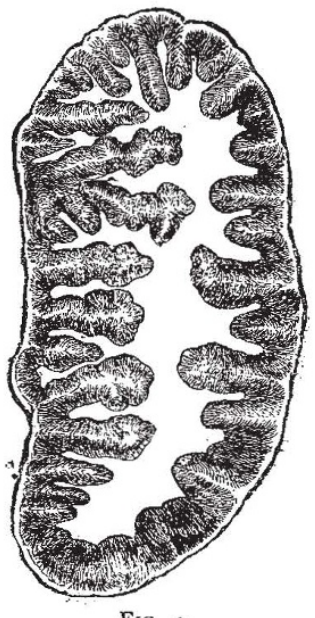

FIG 4

the thickness of the enamel, takes place in marsupials with such constancy, as to be almost a class characteristic." This condition is seen in Fig. I, where A is the dentine, $B$ the enamel, and $C$ one of the dentinal tubes which enters the latter at the point where its course is most bent, and the smaller lateral ramifications cease.

It is with regard to the development of the teeth that Mr. Tomes gives us most valuable information, especially

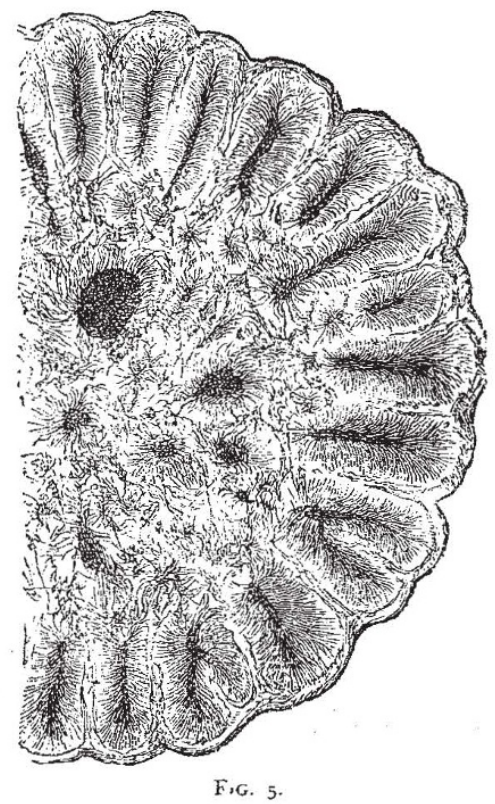

amorg the fish, amphibia, and reptiles, and his argument as to their homologies, deduced from their condition in the sharks, is so well stated that we cannot refrain from quoting it. We read that "if a young dog-fish just about to be hatched be examined, it will be found that it has no distinct under lip, but that its skin turns in under its rounded jaw without interruption. The skin outside carries spines (placoid scales), and these spines are cor:tinued over that part of it which enters the mouth and bends over the jaws; only they are a little larger in this latter position. If the growth of the dog-fish be followed, these spines of the skin which cover the jaws become developed to a far greater size than those outside, and the identity and continuity of the two become to some extent masked. No one can doubt, whether from the comparison of the adult forms or from a study of the development of the parts, that the teeth of the shark [and dogfish] correspond to the teeth of other fish, and these again to those of reptiles and mammals ; it may be clearly demonstrated that the teeth of the shark are nothing more than highly developed spines of the skin, and therefore we infer that all teeth bear a similar relation to the skin. This is what is meant when teeth are called dermat appendages, and are said to be perfectly distinct from the internal bony skeleton."

We reproduce a woodcut (Fig, 2) representing a transverse section of the active and reserve poison-fangs of a viper, in which $I$ is the tooth in use, the other numbers being affixed to those which will succeed when that has dropped or been withdrawn by mechanical violence in the order of their succession, they being arranged, as can be seen, in pairs. It is shown that this system of

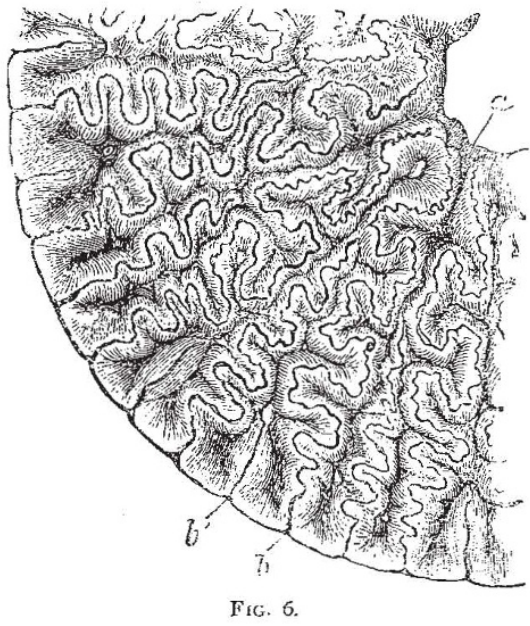

paired series does not exist in the cobra, in which the successional teeth form but a single series; and it is suggested that "perhaps this may serve to explain the preference of the snake-charmers for the cobra, which would probably take longer to replace a removed poisonfang than a viperine snake would."

The striking resemblance between a transverse section of the dentine in the Ray Myliobates and the Edentated mammal, the Aard-Vark (Orycteropus) of South Africa is well illustrated in Fig. 3 ; as in Figs. 4, 5, and 6 are the steps, through the Monitor Lizard (Fig. 4), and the American Bony Pike (Fig. 5), by which a tooth, apparently so elaborate as that of the extinct Labyrinthodon (Fig. 6) - consequently so named by Prof. Owen-may be assumed to have been arrived at by a gradual increase in the number and the depth of the numerous inflections of the pulp-papilla.

Mr. Tomes takes an extremely broad view of the mammalian tooth series, and, instead of following the but too frequent method of specialists, is willing to admit that similarity in dentition is not always associated with classificational affinity. As an instance of this we read that " it is very easy for us to see how a rodent type of dentition is beneficial to its possessor by rendering accessible articles of food wholly unavailable for creatures which have no means of gnawing through a shell or other hard body. Now it happens that in three regions of the world, 
pretty completely cut off from one another, three animals, in parentage widely dissimilar, have arrived at dentitions of rodent type. Thus in Australia, a region practically wholly monopolised by marsupials, a marsupial, the Wombat, has a dentition very much like an ordinary placental rodent. In the island of Madagascar, which is, with the exception of a few mice, without indigenous rodents, a lemurine animal, the Cheiromys [Aye-aye], has a dentition modified in a similar direction; and elsewhere, scattered over the world, we have the ordinary rodents. In fact, three creatures, as widely different in parentage as they well could be, have been modified by natural selection until they have dentitions, not identical, but for practical purposes not unlike."

In one instance we think that Mr. Tomes has gone a little too far in his generalising proclivities, and this is with reference to the canine teeth, when we are told that "it would practically be very inconvenient to abolish the term canine, but it should be borne in mind that its significance is merely equivalent to caniniform premolar, and that in describing the dog's dentition we should be less liable to be misinterpreted were we to say that it has five premolars, of which the first is caniniform." This unwillingness to recognise the canine tooth as an element of the dental series makes Mr. Tomes, as do M. MilneEdwards and some other naturalists, include the lower "canines" of the ruminant ungulata, and lemurs, with the incisors. This, however, is quite opposed to the wellsupported doctrine that in placental mammals there are never more than three incisors in each side of each jaw, and if extended to its logical consequences must render it necessary that the lower incisors of all mammals should be termed incisiform premolars, a very awkward predicament. We all accept it as a fact that the definition of a "canine" tooth is not established upon so distinct a footing as a premolar and a molar, or an upper incisor; but any argument which attempts to annihilate its entity does away with the lower incisors also. In an animal like the Musk Deer (Moschus moschiferus), where the premolars are gradually reduced from behind forwards, how is it, it may be asked, that the upper canine tooth does not, if a premolar, participate in the reduction? Reversely it is immensely exaggerated in size.

Attention is drawn to an important fact recently arrived at by M. Pietkewickz, that, contrary to the statement of Goodsir, there are no traces, even in the youngest examples, of rudimentary upper incisors in the true Ruminantia.

There is another minor point in which we would differ from Mr. Tomes. Speaking of the Perissodactylate and Artiodactylate Ungulata, it is said that "the distinction between the two groups is strongly marked, if living animals alone be considered; but, as Prof. Huxley has pointed out, increasing knowledge of fossil forms is tending to break down the line of demarcation." Our experience is otherwise, and we cannot see between Coryphodon and Anoplotherium any nearer affinities than between the Tapir and the Hippopotamus. It is quite beyond our comprehension that an animal with the axis of the limb running through the middle of the median digit should be allied to a similar creature in which the axis runs between the third and fourth digits, except in times when no such special axis of support existed; that is, before the Ungulata came into existence as such.

In conclusion we cannot do. better than recommend this valuable work by Mr. Tomes to students, not only to those who make the diseases of the teeth their special study, but also to others who are endeavouring to obtain reliable information on the comparative anatomy of these organs, which from their variations and complexity in different animals, have yielded and for a long time yet to come will continue to yield, so large a field for zoological investigation.

\section{FORMATION OF RAINDROPS AND HAIL- STONES ${ }^{1}$}

WHEN the particles of water or ice which constitute a cloud or fog are all of the same size, and the air in which they are sustained is at rest or is moving uniformly in one direction, then these particles can have no motion relatively to each other. The weight of the particles will cause them to descend through the a $r$ with

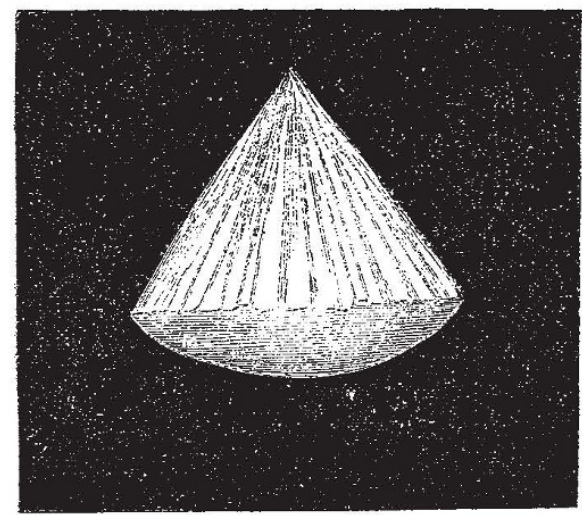

F.G. I.-Perfect Hailstone.

velocities which depend on their diameters, and since they are all of the same size, they will all move with the same velocity.

Under these circumstances, therefore, the particles will not traverse the spaces which separate them, and there can be no aggregation so as to form raindrops or hailstones.

If, however, from circumstances to be presently considered, some of the particles of the cloud or fog attain a larger size than others, these will descend faster than the others, and will consequently overtake those immediately beneath them; with these they may combine so as to form still larger particles which will move with greater velocity, and more quickly overtaking the particles in front of them will add to their size at an increasing rate.

Under such circumstances, therefore, the cloud would

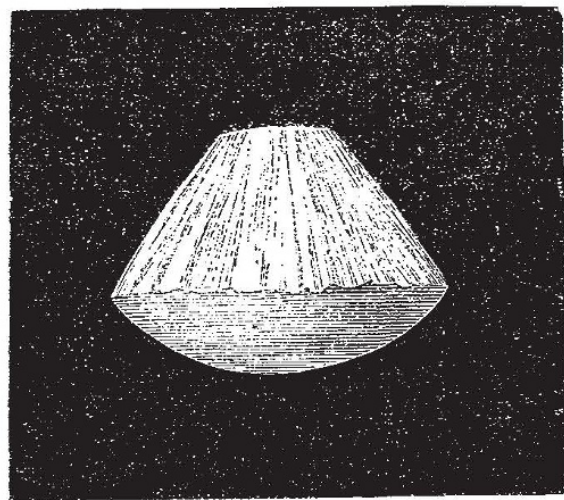

Fig. 2.-Broken Hailstone.

be converted into rain or hail according as the particles were water or ice.

The size of the drops from such a cloud would depend simply on the quantity of water suspended in the space swept thiough by the drop in its descent, that is to say,

I Abstract of paper "On the Manner in which Raindrops and Hailstones are Formed," by Prof. Osborne Reynolds, M.A., read at the Literary and Philosophical Society, Manchester. 